\title{
Effectiveness Analysis of Transverse Rumble Strip using the Image Processing Technique
}

\author{
Mohd Erwan Sanik, Ahmad Hakimi Mat Nor, Nor Baizura Hamid
}

\begin{abstract}
Transverse rumble strip is a traffic calming device which usually installed at the vicinity of schools and accident prone spots. The Malaysia Public Work Department has introduced the latest high performance thermoplastic rumble strips as an intervention along blackspot stretches in Malaysia. This study was carried out to investigate the effectiveness of the new rumble strips installed at SMK Sri Lalang in Kluang, Johor, with respect to the operational speed variation immediately upstream and downstream of the rumble strips area. Operational speed data acquisition was carried out by using the unmanned aerial vehicle or drone and image processing technique. Drone can be used as an alternative to other image recording devices such as telescopic mast. The presence of a drone is often unnoticed by drivers thus giving the advantage of obtaining naturalistic data. The footages from drone were analysed using the image processing technique to ensure every vehicles were taken into account, compare to handheld device such as speed laser gun that can only detect speed of selected vehicles. The operational speeds were analyzed to obtain parameters namely pace, median, and 85th percentiles speed. The results proved that the new rumble strips succeed to reduce speed of vehicles from 7 to 13 kilometer per hour, which are 7 to 18 percent from the initial speed, respectively.
\end{abstract}

Index Terms: High Performance Thermoplastic, Image Processing, transverse rumble strips, Unmanned Aerial Vehicle

\section{INTRODUCTION}

Speeding is one of common behavioral issues among drivers that contribute to vehicle crash or accident. According to the Malaysian Institute of Road Safety Research (MIROS), crash compatibility, fatigue, risky driving and speeding are the most critical factors to be addressed to reduce death due to road accidents [1]. In 2016, death caused by road accident reaches 7,152, the worst in 10 years [2]. In the Road Safety Plan of Malaysia 2014-2020, "reduction in speed" was stated as the main ultimate outcome (UO) in four out of five strategic pillars [3]. One of the strategies to achieve reduction in speed is the traffic calming technique. The most common traffic calming device installed at midblock is the thermoplastic rumble strips.

According to the International Road Assessment Programme

Revised Manuscript Received on July 12, 2019

Ts. Mohd Erwan Sanik, Spatial Investigation of Civil Engineering (SpICE) Group, Centre for Diploma Studies, Universiti Tun Hussein Onn Malaysia, Pagoh, Malaysia.

Ahmad Hakimi Mat Nor, Spatial Investigation of Civil Engineering (SpICE) Group, Centre for Diploma Studies, Universiti Tun Hussein Onn Malaysia, Pagoh, Malaysia.

Nor Baizura Hamid, Spatial Investigation of Civil Engineering (SpICE) Group, Centre for Diploma Studies, Universiti Tun Hussein Onn Malaysia, Pagoh, Malaysia.
(iRAP) [4], the transverse rumble strips are devices that placed across the traffic lane to alert motorists to hazards ahead such as bends, intersections or areas of pedestrian activity. They are most effective where drivers have been travelling at sustained high speed for long periods. The cost is considerably low with treatment life of 1 to 5 years and the effectiveness is 10 to 25 percent [4]. In this study, researchers investigate the effectiveness of new high performance thermoplastic (HPT) installed on Federal Route FT50, specifically at SMK Sri Lalang. Furthermore, this study also introduced and expanded the use of unmanned aerial vehicle (UAV) or drone in traffic research in Malaysia. UAV offer a more non-intrusive way of recording traffic phenomena especially in obtaining naturalistic data [5].

\section{RELATED WORKS}

\section{A. Application of Unmanned Aerial Vehicle (UAV) in Traffic Study}

UAV has been used by many researchers in various field, include traffic study. The main advantage of using UAV is the coverage of images and videos is wide and clear enough to extract necessary traffic data. The images are usually analyzed to obtain meaningful findings such as flow rate, operational speed, and gap and headway data. Later, such findings can be interpreted to define the performance of a road facility and to comprehend the drivers' behavior. Barmpounakis et al. [5] have listed 37 past researches (year 2000 until 2016) related to traffic study that use of UAV in data acquisition. Of these, 14 researches used UAV for numerical traffic data such as traffic count, speed, gap and density [5-18]. Others were more to surveillance works. Mirchandani et al. [6] discussed the potential of collecting traffic data from aerial video footage and several parameters were able to be extracted, such as densities, travel times, turning counts, queue lengths etc. In Salvo et al. [7], authors dealt with macroscopic models comparison using airborne video data. In Salvo et al. [8], authors compared speed data that were acquired via GPS and UAV video footage data, with the results showing small deviations between the two measurements. Xin et al. compared vehicle speeds that were acquired from UAV with speed measurements from ground radars, with over $90 \%$ accuracy [9].

\section{B. Operational Speed}

Operating speed is normally 
represented by 85 th percentile of the speed distribution under free flow conditions [19]. The 85th percentile is the speed at which $85 \%$ of the observed vehicles are traveling at or below. This speed is usually denoted as posted speed limit, assuming that $85 \%$ of the drivers are traveling at a speed they perceive to be safe [20]. Operating speed may be defined with speed values such as the average, pace, or 85 th percentile speeds [21]. The 85th percentile of the distribution of observed speeds is the most frequently used measure of the operating speed associated with a particular location or geometric feature [22]. However, several studies have demonstrated that 85 th percentile operating speeds typically exceed posted speeds and also show that the 50th percentile operating speed either is near or exceeds the posted speed limit [23].

\section{Reduction in Speed at Rumble Strips}

A rumble strip is a raised or grooved pattern placed on the pavement surface of a travel lane, provide motorists with an audible, visual, and tactile warning that their vehicle is approaching a decision point of critical importance to safety. [24]. A reduction of $6.4 \mathrm{~km} / \mathrm{h}$ is required by rumble strips to be practically significant [25]. In a study on effectiveness of rumble strips at intersection approaches, the overall trend was for speed change reductions to be equal to or less than $1.6 \mathrm{~km} / \mathrm{h}$ [24]. Paul and Jeff summarized five before-and-after speed studies performed involving transverse rumble strips, which the actual reductions in speeds have been in the range of 3.2 to $12.9 \mathrm{~km} / \mathrm{hr}$, which may be barely perceptible to the traveling public [26].

\section{METHODOLOGY}

\section{A. Study Location}

This study was carried out at Jalan Kluang of Federal Route FT50, specifically in front of SMK Sri Lalang, Kluang Johor. The JKR has installed the HPT transverse rumble strips at study location in April 2017 as a road safety intervention, part of the Mysafe Road @ Batu Pahat Strategic Plan 2016 - 2017. The illustration of rumble strips arrangement is as shown in Fig. 1. While, the overall aerial image of study location is as shown in Fig. 2.

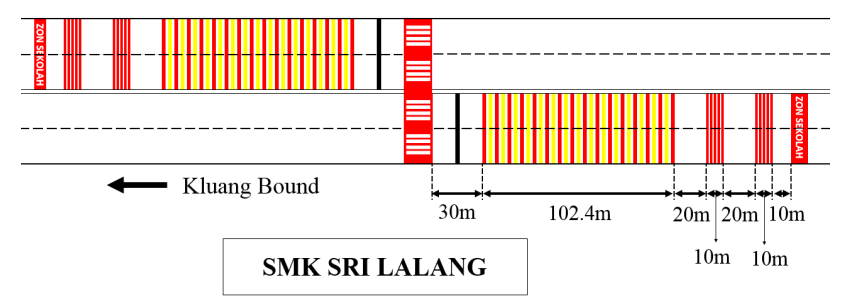

Fig. 1 Arrangement of HPT rumble strips in front of SMK Sri Lalang, which consists of 26 bars each direction (10 red thin bars and 16 red bars slot between existing yellow bars).

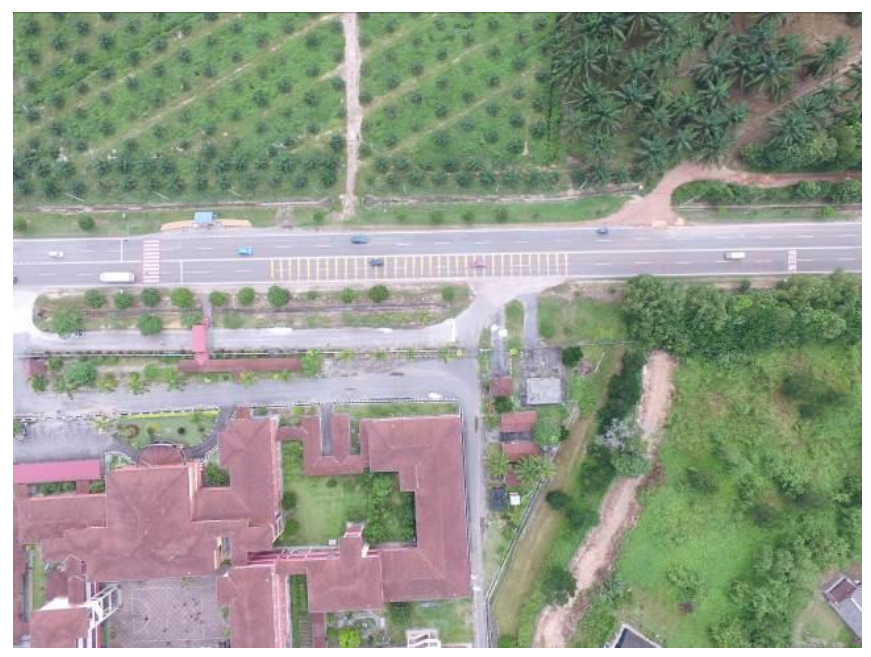

Fig. 2 Aerial view of the HPT rumble strips on the Kluang bound stretch (captured by the UAV at the height of 120 meters from ground).

\section{B. Data Acquisition}

Data collection was carried out using two units of Phantom 3 Advance which were flied simultaneously. Speed data were then extracted using the image processing software. Fig. 3 shows the data collection activity.

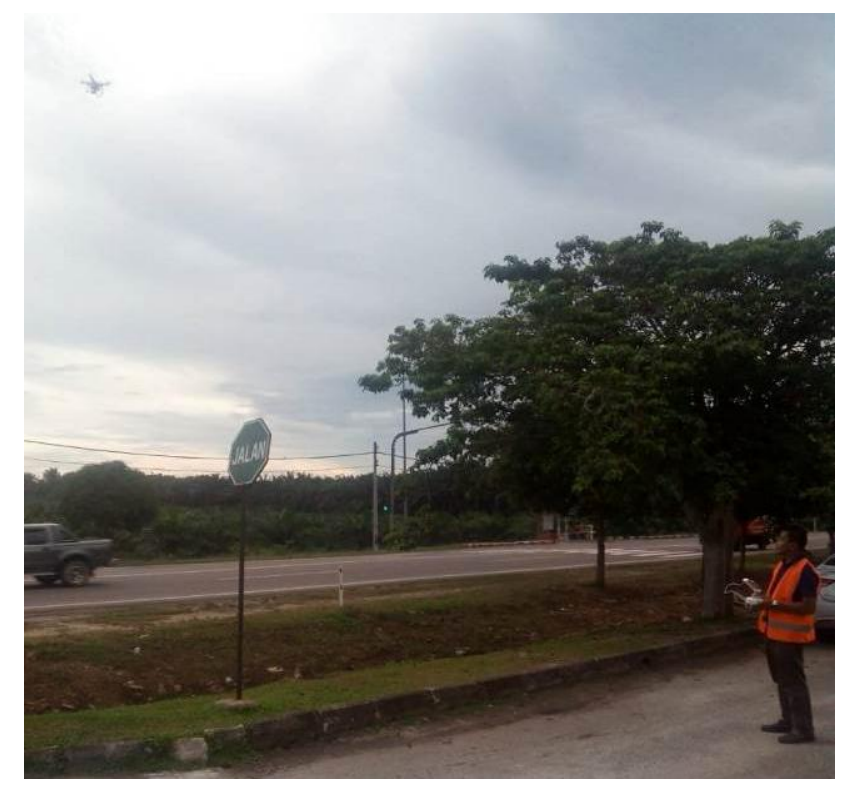

Fig. 3 One of the authors was flying the UAV to record video at study location for data collection at upstream of HPT rumble strips.

The UAV was flown at the height of 15 meters from ground, optimum height that was identified during the field data collection of commuter traffic heading towards Kluang, as shown in Fig. 4. Optimum height is referred as the height of the suitable coverage of aerial footage for image processing analysis purposes. The points of spot speed identification at upstream (before) and downstream (after) the HPT rumble strips were 100 and 50 meters from the start and the end of markings, respectively. 


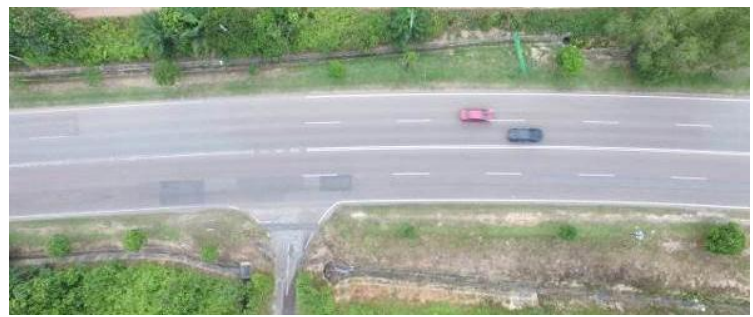

(a)

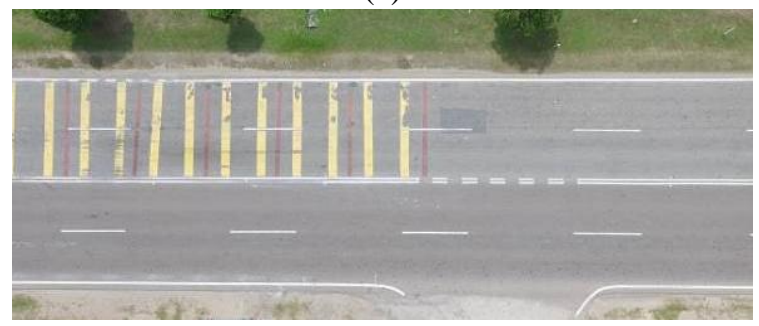

(b)

Fig. 4 Static aerial view image for (a) immediately upstream and (b) downstream the studied HPT rumble strips of Kluang bound.

\section{Data Extraction}

Individual speed data were extracted lane by lane from the recorded videos using the image processing software, as shown in Fig. 5 and 6.

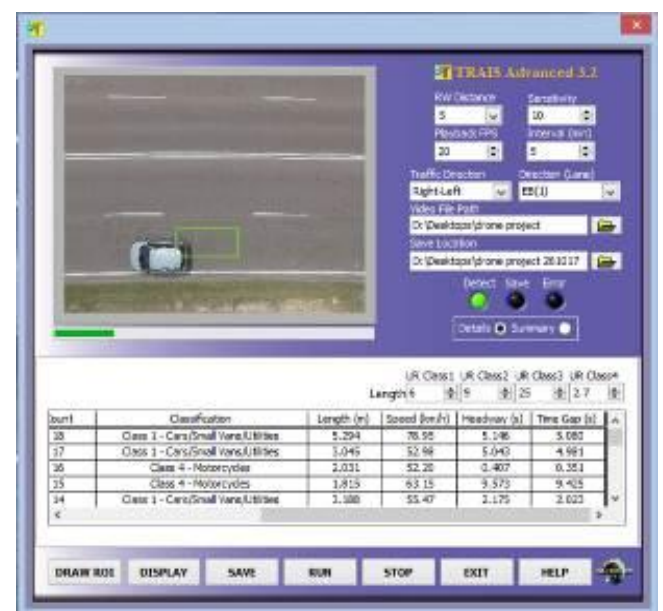

(c)

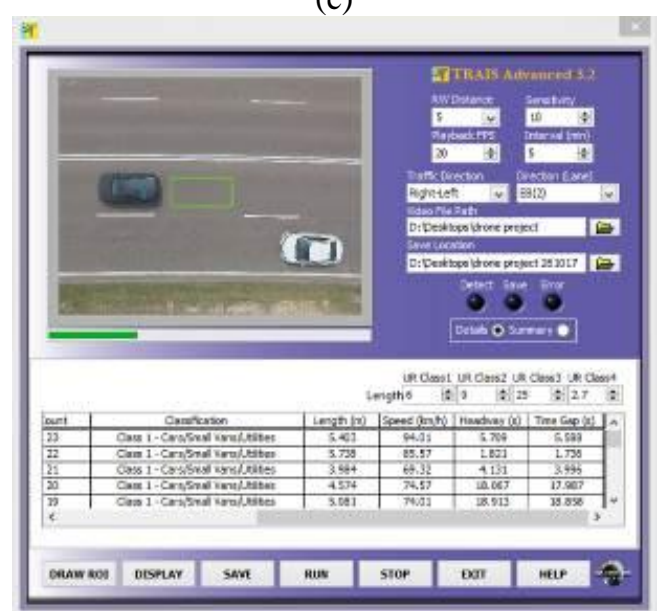

(d)

Fig. 5 Interfaces of image processing software during data extraction. (a) Upstream left lane, (b) Upstream right lane.

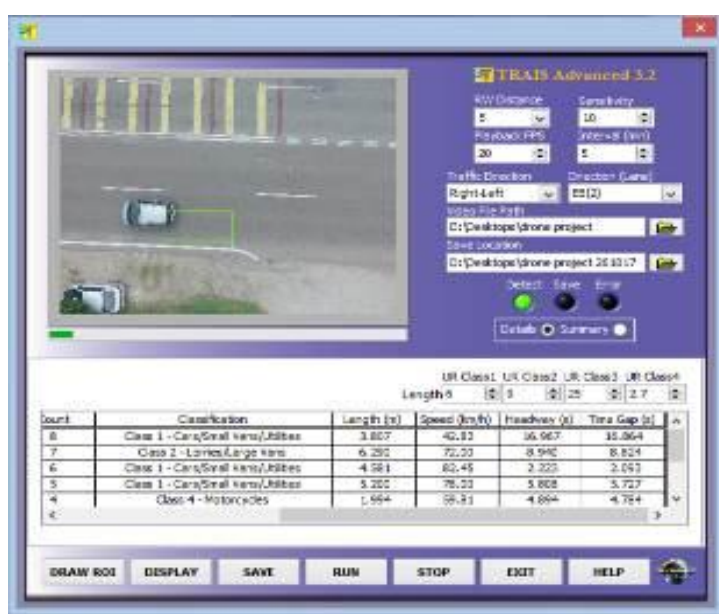

(a)

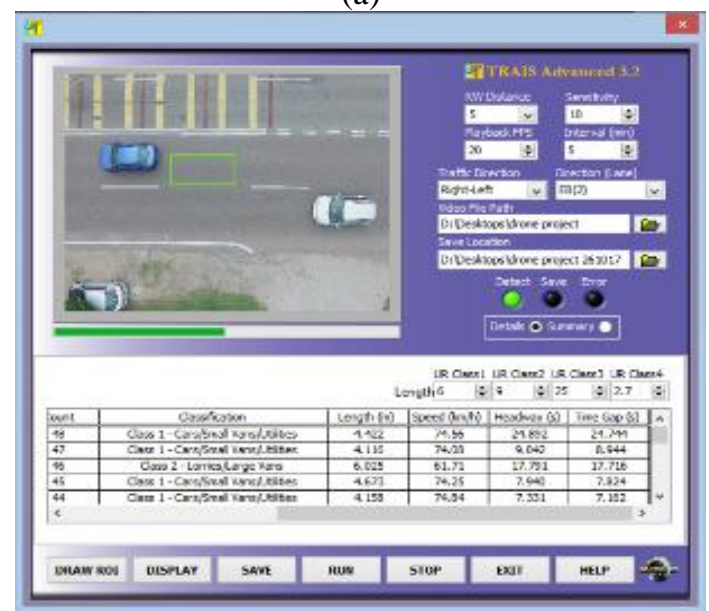

(b)

Fig. 6 Interfaces of image processing software during data extraction. (a) Downstream left lane, (b) Downstream right lane.

\section{RESULTS AND DISCUSSION}

\section{A. Traffic Composition}

Based of extracted data, the total number of vehicles that were analyzed in this study for upstream and downstream were 178 and 209 vehicles, respectively. Data were collected during off-peak hours in order to obtain a free flow condition. Although data were collected at the same time, the number of vehicles is slightly different due to the efficiency of image processing software. Vehicle samples were categorized into 4 classes and the percentage of composition is as shown in Fig. 7. While Table 1 shows the lane distribution at upstream and downstream of rumble strip. Referring to Table 1, lane distribution was nearly balanced. Therefore, the lane changing activity was limited along rumble strips area. 


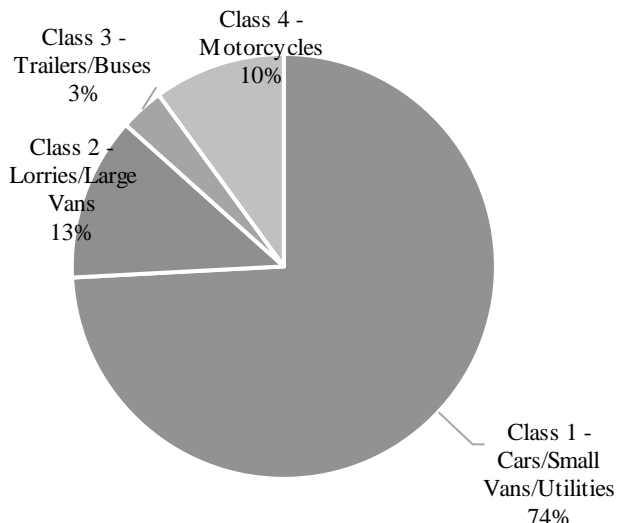

Fig. 7 Traffic composition (in percentage) for this study, showing that Class 1 contribute the largest vehicle samples, followed by Class 2, Class 3, and Class 4 .

Table 1 Lane distribution of traffic at study location.

\begin{tabular}{ccccc}
\hline \multirow{2}{*}{ Location } & \multicolumn{2}{c}{ Left } & \multicolumn{2}{c}{ Right } \\
& no. & \% & no. & \% \\
\hline Upstream & 94 & 52.8 & 84 & 47.2 \\
Downstream & 106 & 50.7 & 103 & 49.3 \\
\hline
\end{tabular}

\section{B. Two-Sample t-test}

The speed data were analyzed using two-sample t-test to determine whether the mean differs significantly. Using the null hypothesis, $\mathrm{H}_{0}$ that the difference is equal to zero and the alternative hypothesis, $\mathrm{H}_{1}$ that the difference is not equal to zero, the result is as shown in Table 2.

Since the speed data were analyzed with $\alpha$-level of 0.05 , a $95 \%$ (or 0.95 ) confidence interval was constructed. Based on the sample data, the result can be $95 \%$ confident that the difference, $\mu$ (Upstream)- $\mu$ (Downstream), is greater than or equal to 5.36 and less than or equal to 10.67. Since the reference value of 0 is not within the confidence interval, the mean of two individual speed groups are not the same and $\mathrm{H}_{0}$ can be rejected with $95 \%$ confidence. The t-value is 5.94 and the associated p-value is 0.000 or less than 0.0005 . This p-value indicates that there is less than a $0.05 \%$ chance that samples would be obtained if $\mu($ Upstream $)-\mu$ (Downstream) was actually 0 . Fig. 8 shows the individual value plot for the t-test.

Table 2 Two-sample t-test result.

\begin{tabular}{ccccc}
\hline & N & Mean & $\begin{array}{c}\text { Standard } \\
\text { Deviation }\end{array}$ & $\begin{array}{c}\text { Standar } \\
\text { d Error } \\
\text { Mean }\end{array}$ \\
\hline Upstream & 178 & 80.4 & 13.9 & 1.0 \\
Downstream & 209 & 72.4 & 12.4 & 0.86 \\
\hline
\end{tabular}

Difference $=\mu($ Upstream $)-\mu($ Downstream $)$

Estimate for difference: 8.02

95\% CI for difference: $(5.36,10.67)$

$\mathrm{T}$-Test of difference $=0(\mathrm{vs} \neq)$ : $\mathrm{T}$-Value $=5.94 \mathrm{P}$-Value

$$
=0.000 \mathrm{DF}=357
$$

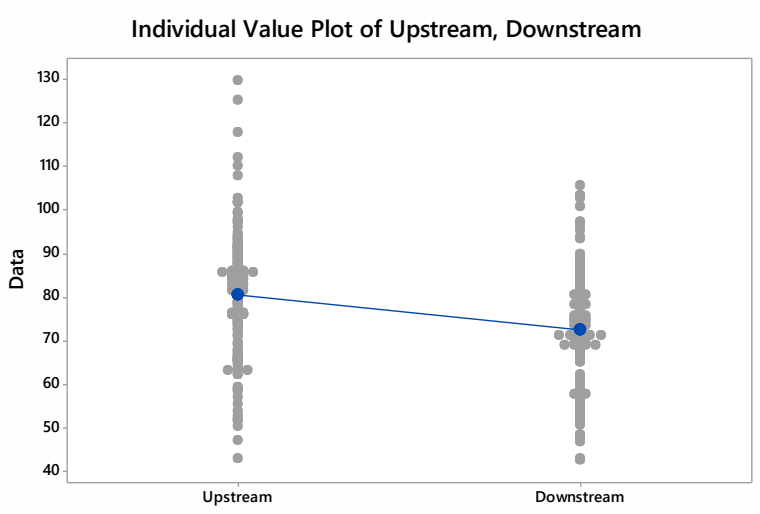

Fig. 8 Individual value plot of upstream and downstream speed data with mean points connecting two group of samples showing the approximate difference of $8 \mathrm{~km} / \mathrm{h}$.

Referring to Fig. 8, from the individual value plots of the speed data, each sample appear to be roughly normally distributed, which is a condition for using the test. It is also evident that mean satisfaction in the upstream speed sample was greater than that for downstream (This was confirmed by the results of the t-test).

\section{Pace, Median Speed and 85th Percentiles}

Data were clustered into several speed classes to obtain percentage of frequency and by using the mid-value and upper limit of each speed class, the frequency distribution and cumulative frequency distribution were developed, respectively. The analysis were carried out separately according to lane in order to observe the lane effect. Fig. 9 and 10 show the left and right lanes frequency distribution curve, upstream and downstream of rumble strips.

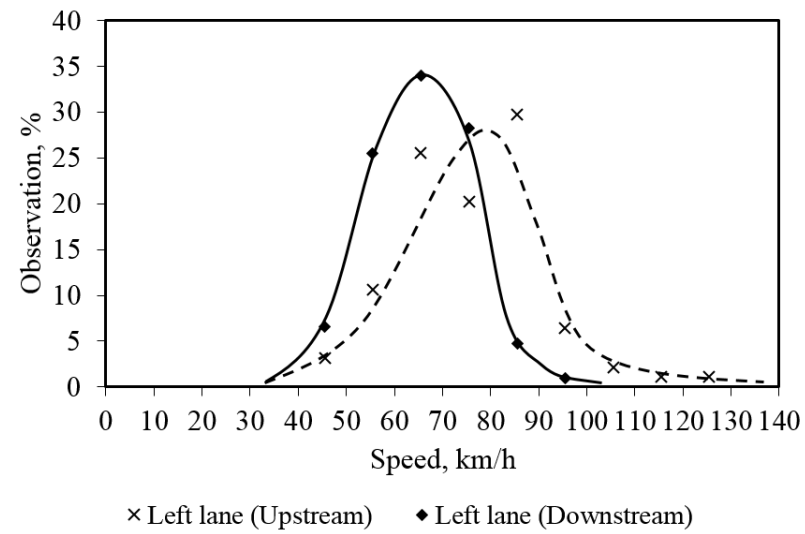

Fig. 9 Frequency distribution curve of upstream and downstream left lane of HPT rumble strips. 


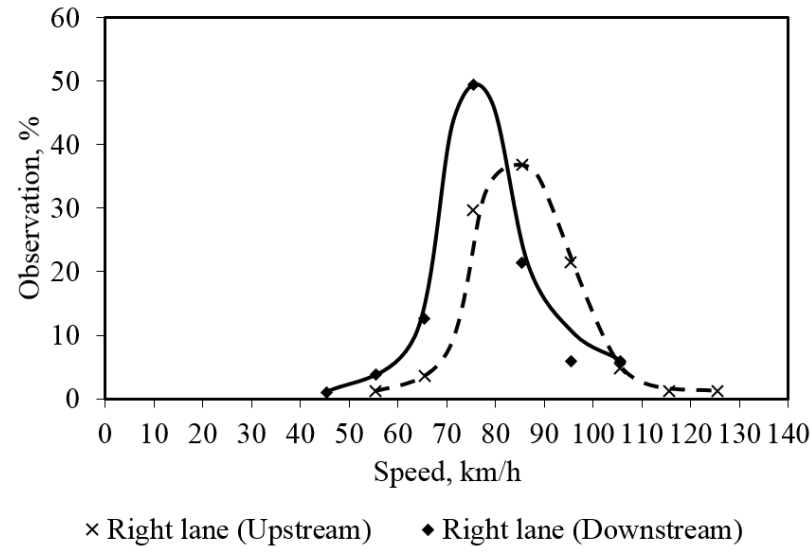

Fig. 10Frequency Distribution Curve of right lane upstream and downstream of HPT rumble strips.

Fig. 11 and 12 show the cumulative frequency distribution of left and right lane upstream and downstream of rumble strips.

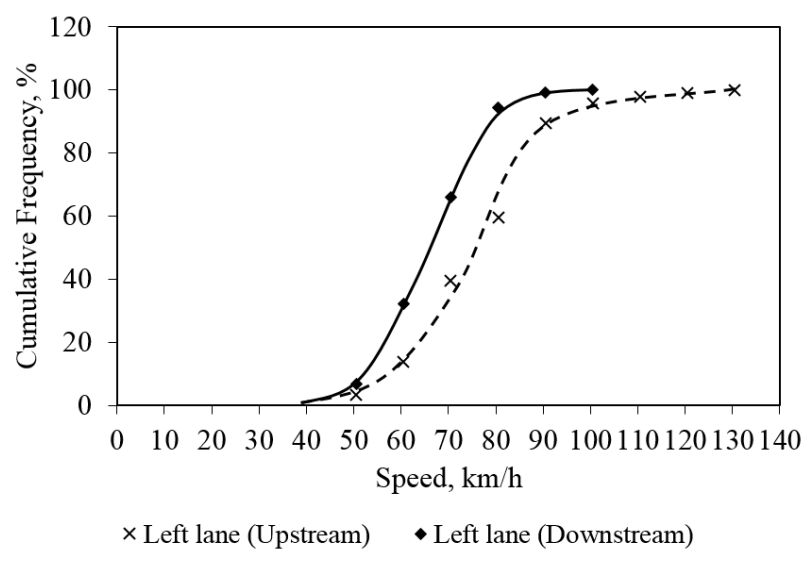

Fig. 11 Cumulative Frequency Distribution curve of left lane upstream and downstream of HPT rumble strips.

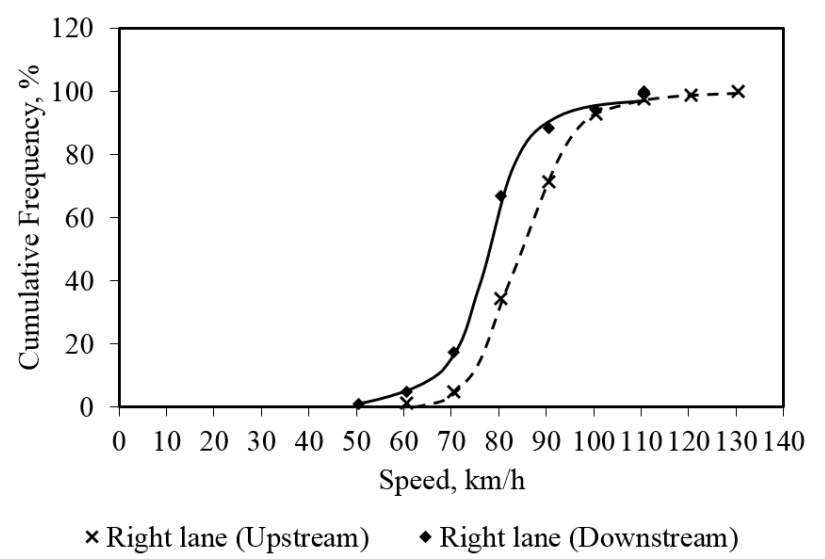

Fig. 12Cumulative Frequency Distribution curve of right lane upstream and downstream of HPT rumble strips.

Fig. 13 shows the frequency distribution curve of both lanes for upstream and downstream of rumble strips.

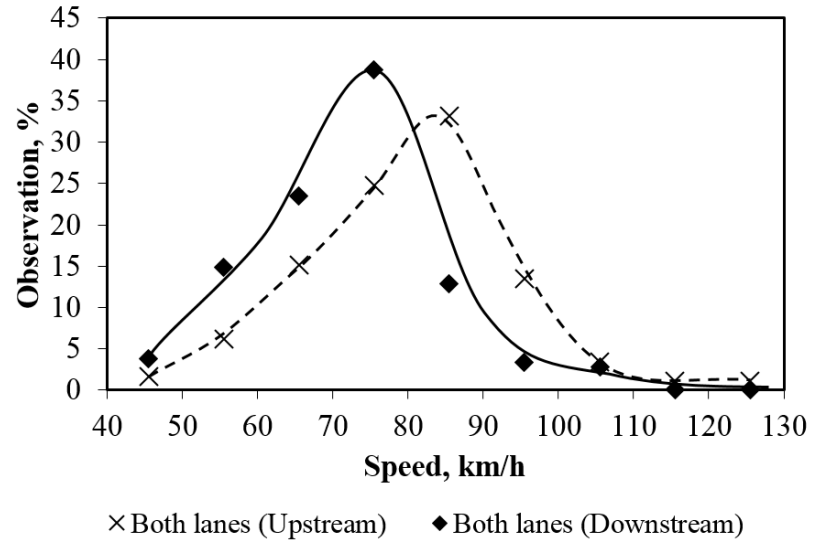

Fig. 13 Frequency Distribution of Speed, immediately upstream and downstream of the HPT rumble strips for both lanes.

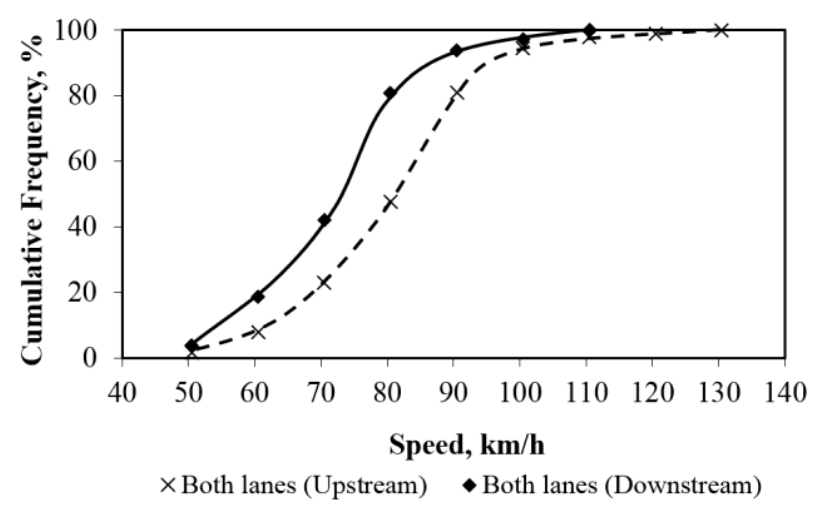

Fig. 14 Cumulative Frequency Distribution of Speed for both lanes.

Table $3 \mathrm{a}$ and $3 \mathrm{~b}$ shows the summary of pace, median and $85^{\text {th }}$ percentiles speed based on outcomes from Fig. 9 through 14.

Table 3a Pace, median and $85^{\text {th }}$ percentiles speed of left, right and both lanes for upstream and downstream HPT rumble strips.

\begin{tabular}{cccc}
\hline Parameter & Lane & Upstream & Downstream \\
\hline \multirow{4}{*}{ Pace } & Left & $74-84$ & $61-71$ \\
& Right & $79-89$ & $70-80$ \\
& Both & $79-89$ & $70-80$ \\
\hline \multirow{3}{*}{ Median } & Left & 77 & 66 \\
& Right & 85 & 77 \\
& Both & 82 & 73 \\
\hline \multirow{3}{*}{ 85th percentile } & Left & 88 & 77 \\
& Right & 95 & 88 \\
& Both & 92 & 83 \\
\hline
\end{tabular}

Referring to Table $3 \mathrm{~b}$, the highest percentage of difference recorded was the pace of left lane while the lowest percentage was the $85^{\text {th }}$ percentiles speed of right lane. However, a similar pattern that can be identified was the left lane records higher differences in speed reduction than the right lane. Moreover, an interesting finding was the speed 
reduction recorded for overall data in both lanes gave a same value of $9 \mathrm{~km} / \mathrm{h}$. On the basis of literature review [25], with reduction greater than $6.4 \mathrm{~km} / \mathrm{h}$, the HPT rumble strips at study location were successful at meaningfully reducing the speeds for the data analyzed.

Table 3b Differences and percentage of differences between pace, median and $85^{\text {th }}$ percentiles speed of left, right and both lanes for upstream and downstream HPT rumble strips.

\begin{tabular}{cccc}
\hline Parameter & Lane & Differences & $\begin{array}{c}\text { \% } \\
\text { Differences }\end{array}$ \\
\hline \multirow{3}{*}{ Pace } & Left & -13 & 18 \\
& Right & -9 & 13 \\
& Both & -9 & 13 \\
\hline \multirow{2}{*}{ Median } & Left & -11 & 14 \\
& Right & -8 & 9 \\
& Both & -9 & 11 \\
\hline \multirow{2}{*}{ 85th } & Left & -11 & 13 \\
percentile & Right & -7 & 7 \\
& Both & -9 & 10 \\
\hline
\end{tabular}

\section{CONCLUSION}

In summary, the values of pace, median and 85th percentiles speed obtained from this study show that there is a significant variation of 7 to 18 percent in data analyzed and HTP rumble strips demonstrate their effectiveness in reducing the speed. Furthermore, drone can be used as an alternative to other image recording devices such as telescopic mast. The presence of a drone is often unnoticed by drivers thus giving the advantage of obtaining naturalistic data such as database from spontaneous driving behavior.

\section{ACKNOWLEDGMENT}

The authors would like to thank the Research Management Centre, Universiti Tun Hussein Onn Malaysia for the fund given under the Tier 1 Research Grant Code H199.

\section{REFERENCES}

1. Malaysian Institute of Road Safety Research (MIROS), MRR 05/2012: MIROS Crash Investigation and Reconstruction Annual Statistical Report 2007-2010. (2012).

2. Jabatan Keselamatan Jalan Raya (JKJR), Statistik Keselamatan Jalan Raya Edisi 2016. (2017) pp. 9.

3. Ministry of Transport Malaysia (MOT), Road Safety Plan 2014-2020. (2004).

4. The International Road Assessment Programme (iRAP), Treatment - Rumble Strips. (2010), Accessed on 29 October 2017. url: http://toolkit.irap.org/default.asp?page=treatment $\& i d=30$

5. Barmpounakis, E.N., Vlahogianni, E.I., Golias, J.C., Unmanned Aerial Aircraft Systems for Transportation Engineering: Current practice and future challenges, International Journal of Transportation Science and Technology (2016), Vol. 5, pp. 111-122.

6. Mirchandani, P., Hickman, M., Angel, A., Chandnani, D., Hickman, M., Application of aerial video for traffic flow monitoring and management. ASCE 7th Int. Conf. Appl. Adv. Technol. Transp. (2002).

7. Salvo, G., Caruso, L., Scordo, A., Urban traffic analysis through an UAV. Proc. - Soc. Behav. Sci. 111, (2014). pp 1083-1091.

8. Salvo, G., Caruso, L., Scordo, A., Guido, G., Comparison between vehicle speed profiles acquired by differential GPS and UAV, 17th Meet. EURO Work. Gr. Transp. EWGT (2014).
9. Xin, Z., Yun-tao, C., Li, L., Jia-ning, G. Algorithm of Vehicle Speed Detection in Unmanned Aerial Vehicle Videos. In: Transportation Research Board 93rd Annual Meeting Compendium of Papers. Washington, D.C. (2014).

10. Braut, V., Culjak, M., Vukotic, V., Segvic, S., Sevrovic, M., Gold, H. Estimating OD matrices at intersections in airborne video - a pilot study. MIPRO, (2012). Proc. 35th Int. Conv., pp. 977-982.

11. Coifman, B., McCord, M., Mishalani, R.G.R. Traffic flow data extracted from imagery collected using a micro unmanned aerial vehicle. Appl. Adv. Technol. Transp. Ninth Int. Conf., pp. 298-303. doi:10.1061/40799(213)47. (2006).

12. Gao, H., Kong, S.L., Zhou, S., Lv, F., Chen, Q. Automatic Extraction of Multi-Vehicle Trajectory Based on Traffic Videotaping from Quadcopter Model. Appl. Mech. Mater. 552, 232-239. http://dx.doi.org/10.4028/www.scientific.net/AMM.552.232. (2014).

13. Li, Y. Fuzzy Image Segmentation from High Resolution UAV Aerial, ISPRS08. p. B3b 529. (2008).

14. Puri, A., Valavanis, K., Kontitsis, M. Statistical profile generation for traffic monitoring using real-time UAV based video data. Mediterr. Conf. Control Autom. 1-6. http://dx.doi.org/10.1109/MED.2007.4433658. (2007).

15. Reinartz, P., Lachaise, M., Schmeer, E., Krauss, T., Runge, H. Traffic Monitoring with Serial Images from Airborne Cameras. ISPRS J. Photogramm. Remote Sens. 61, 149-158. http://dx.doi.org/10.1016/j.isprsjprs.2006.09.009. (2006).

16. Salvo, G., Caruso, L., Scordo, A. Gap acceptance analysis in an urban intersection through a video acquired by an UAV 199-205. (2013).

17. Wang, H., Duan, S., Zheng, Y., Liu, S., Dong, C., Li, Y.. Using model aircraft to collect vehicle trajectory data. Transp. Res. Board 93rd Annu. Meet. Compend. Pap. (2014).

18. Zhang, L., Peng, Z., Sun, D.D.J., Liu, X. A UAV-based automatic traffic incident detection system for low volume roads. Transp. Res. Board 92nd Annu. Meet. pp. 1-19. (2013).

19. Filippo, G.P. \& Marinella, G., Modeling Operating Speed of Two Lane Rural Roads. Procedia - Social and Behavioral Sciences 53 (2012) pp. 664 - 671.

20. Center for Transportation Research and Education, Handbook of Simplified Practice for Traffic Studies: Spot Speed Study. (2009).

21. Manual on Uniform Traffic Control Devices for Streets and Highways (Millennium Edition), Federal Highway Administration, U.S. Department of Transportation, Washington, DC (2000).

22. American Association of State Highway and Transportation Officials. A Policy on Geometric Design of Highways and Streets (2001).

23. Transportation Research Board (TRB), NCHRP Report 504: Design Speed, Operating Speed, and Posted Speed Practices. (2003)

24. Tyrell D.T., Mark W.B., and Paul J.C., Speed Changes Due to Transverse Rumble Strips on Approaches to High-Speed Stop-Controlled Intersections. Transportation Research Record: Journal of the Transportation Research Board, No. 1973, Transportation Research Board of the National Academies, Washington, D.C., 2006, pp. 1-9.

25. Dudek, C. L., R. D. Huchingson, F. T. Creasey, and O. J. Pendleton. Field Studies of Temporary Pavement Markings at Overlay Project Work Zones on Two-Lane, Two-Way Rural Highways. In Transportation Research Record 1160, TRB, National Research Council, Washington, D.C., 1988, pp. 22-34.

26. Paul, J.C, Jeff, D.M., Effectiveness of Rumble Strips on Texas Highways: First Year Report. Texas Transportation Institute. (2003). 